have gained in cogency by including a

Palestinian perspective.

Were there reason to believe that Palestinian scientists could participate freely in such collaborations, unimpeded by arbitrary and unpredictable curfews imposed by an occupying army, denying them access to their own laboratories, not to mention European hosts, those of us who signed the call for a moratorium — not an unlimited boycott — might not have felt compelled to take such a drastic step.

Ahmed Abbes*, Mikhael Balabane*, Emmanuel Farjoun $\dagger$, Michael Harris $\ddagger$, Raphael Rouquier $\ddagger$, Pierre Schapira $\$$ *Université Paris 13, 99 Avenue Jean-Baptiste Clément, 93430 Villetaneuse, France $\dagger$ Hebrew University of Jerusalem, Jerusalem 91904, Israel $\ddagger$ Université Paris 7, 2 place Jussieu, 75251 Paris Cedex 05, France §Université Paris 6, 75252 Paris Cedex 05, France

\section{Efforts to build bridges in the Middle East}

Sir - I was delighted to see the Opinion article "Don't boycott Israel's scientists" (Nature 417, 1; 2002).

I do not pretend to be impartial: my father, his brother and sister survived the Shoah, but the entire rest of his family (more than 30 aunts, uncles and cousins) perished; I have spent each of my sabbaticals partly in Israel, have sponsored students and post-docs from Israel, and have binational science foundation grants.

I also serve on the Science Advisory

Board of the Arava Institute of

Environmental Studies, which attempts to simultaneously do good science and build bridges between Israel and its Arab neighbours.

I count Patrick Bateson as one of my friends and grieved to see him leading the UK scientists in the direction of a boycott.

Your Opinion article beautifully articulates the reasons for continuing to support Israeli science.

Marc Mangel

Department of Environmental Studies, 39 Natural Sciences 2, University of California, Santa Cruz, California 95064, USA

\section{Taxonomists need better access to published data}

Sir - The biodiversity community must learn from its counterparts in the physical and biomedical sciences and move towards the provision of unhindered access to its baseline data: taxonomic descriptions, imagery, geographical and temporal distribution, and characters - molecular, morphological and behavioural (see H. C. J. Godfray's Commentary "Challenges for taxonomy”, Nature 417, 17-20; 2002).

International codes of nomenclature require taxonomic actions to be published, and the data thus made available. Yet much of the underlying information is accessible only by examination of the specimens involved, so access is in effect limited to all but a few potential users. The assertion of copyright by publishers further limits the distribution of published information.

Very few libraries around the world have the financial capacity to carry the full range of literature in which systematic results are published. To take the ants as one example, the 11,000 species were first formally described in approximately 3,800 publications - roughly 100,000 printed pages — in more than 800 serials and monographs.

As F.-T. Krell noted in Correspondence (Nature 415, 957; 2002), the relevance of taxonomic publications remains high for many years. Although funding has been secured to make $80 \%$ of the ant pages accessible online within the next two years at www.antbase.org (see Nature 416, 115; 2002), many recent papers are not in the public domain because of publishers' copyright restrictions.

To chart even the $1-1.5$ million "known" species of the world (E. O. Wilson, Science 289, 2279; 2000) is a daunting task. International initiatives such as the Global Biodiversity Information Facility are needed to help people work effectively towards that goal, as are the development of tools from information technologies and a new cultural approach to ownership and sharing of data.

In the genomics community, authors place all sequence data in a publicly accessible depository. As a result, the data themselves can be peer-reviewed, and new areas of investigation have developed through comparison and collation of data sets.

The biodiversity and conservation communities would greatly benefit from similar provision of open access to character and distributional data. Because of space and cost constraints, many of these data are unpublished. We sorely need a mechanism to provide access to these data, along the lines of GenBank, as well as the cultural imperative to deposit data (see Godfray's Commentary for a proposal to make taxonomy a web-based unitary discipline).

For now, it would be a tremendous benefit if publishers would make published taxonomic papers open-access, so that an equivalent to PubMed can make this important scientific information available to the broadest possible community.

Donat Agosti ${ }^{\star}$, Norman F. Johnson $\dagger$

${ }^{\star}$ American Museum of Natural History, New York, New York 10024-5192, USA

$\dagger$ Insect Collection, Ohio State University,

Columbus, Ohio 43210-1220, USA

\section{Advocacy and analysis}

Sir - Roger A. Pielke, in his Commentary "Policy, politics and perspective" (Nature 416, 367-368; 2002) argues that scientists should not be advocates; that research should be communicated to society through policy analysts. Unlike the advocate, who subordinates science to one narrow vision of its social implications, he says that the analyst "increases the range of alternatives available to decision-makers by clearly associating scientific results with a range of choices and outcomes".

Pielke objects to natural scientists who simply advocate more research to help solve social problems - but he then argues something similar for his own form of science: social-science policy analysis. Pielke is right that more social-scientific research and analysis of science and its results would be beneficial. But with this argument, is he not as much an advocate as those he criticizes?

\section{Carl Mitcham}

Liberal Arts and International Studies, Colorado School of Mines, Golden, Colorado 80401, USA

\section{Specimen collecting is still vital for research}

Sir - The monumental data set assembled and analysed by Ernst Mayr and Jared Diamond in their monograph The Birds of Northern Melanesia, reviewed by Stephen Pruett-Jones (Nature 415, 959-960; 2002), was based in part on museum skin specimens obtained during general collecting expeditions over many years.

An unwillingness to acknowledge the role of specimens in scientific research is contributing to the deterioration of avian biodiversity collections and is hindering the thorough collecting that is so necessary for future studies. It has been argued that further collecting is unnecessary even in poorly inventoried areas, despite clear evidence to the contrary.

Seminal works such as Mayr's and Diamond's rely on specimen foundations in museums. It is essential to acknowledge this, so that the avian specimen base can be expanded, understood and supported. Angelo Capparella Department of Biological Sciences, Illinois State University, Normal, Illinois 61790-4120, USA 